\title{
Marijuana is not a prescription medicine
}

\author{
John Fletcher MB BChir MPH
}

$\mathrm{W}$ hat role should doctors play in the control of marijuana? Health Canada in a news release late last year announced proposals for "new Marihuana for Medical Purposes Regulations," suggesting that "changes improve public safety [and] maintain patient access."' The document goes on to suggest that "the proposed new Marihuana for Medical Purposes Regulations aim to treat marihuana as much as possible like any other narcotic used for medical purposes."' Under the existing regulations, it is the federal minister of health who issues a patient with authorization to possess marijuana. Under the proposed new regulations, it is doctors, or possibly other health practitioners, who will issue "a medical document, similar to a prescription" allowing their patient to obtain marijuana. The language is soothing and suggests that marijuana is a medicine, albeit one that needs special oversight like morphine and for which users may be seen as patients in certain circumstances. It is but a small step from here to suggest that doctors should prescribe marijuana for medical indications. But is marijuana a medicine? Or, more specifically, is it a prescription medicine?

Marijuana is certainly pharmacologically active, but that is also true of a large number of compounds that are not medicines, such as dry cleaning fluid. Marijuana may be used to relieve pain and appears to be effective in this role for some people. ${ }^{2}$ Hence, it is a drug, but then so are many other plants that are not used as prescription medicines such as St John's wort or belladonna. What characterizes a prescription medicine is that it has an identifiable compound or active ingredient that has a known potency in its pure form; its pharmacokinetics and route of delivery are understood; it is delivered safely; it is manufactured with a consistent formulation; and it has undergone regulatory studies and been approved as having a favourable balance of benefits and harms. Several prescription medicines have already been developed from cannabis, ${ }^{1}$ but under the proposed new regulations, marijuana itself has none of the above characteristics. Doctors are being asked to prescribe a dried leaf containing several compounds of unspecified potency, some of them active and none of them pure; smoking is an unreliable way to deliver a consistent dose, is probably harmful and no other medicine is administered this way; there is no evidence that those offering to supply marijuana understand how to deliver a consistent drug dose in a smoked product; and, most important, marijuana has not undergone regulatory testing and approval as a medicine.

Marijuana is a drug that is at a similar stage of development to poppy and foxglove in the 19th century. Although doctors may have prescribed those drugs then, in the 21st century we prescribe morphine and digoxin. If the government is serious about asking doctors to prescribe marijuana, it should remove the barriers to developing marijuana as a pharmaceutical product. Then doctors would have a medicine they could prescribe with some knowledge as to its effectiveness and side-effect profile, safe in the knowledge that they are not alone in the firing line should something go wrong. But there is no suggestion in the recent announcement that this is the government's intention.

The real impetus for change is probably to control the use of this illegal substance and to reduce the risk of fire from home growing operations. In her announcement of the proposed new regulations, Minister of Health Leona Aglukkaq said "Current medical marihuana regulations have left the system open to abuse. We have heard real concerns from law enforcement, fire officials and municipalities about how people are hiding behind these rules to conduct illegal activity and putting health and safety of Canadians at risk."' These are real concerns. The number of people authorized to use marijuana has grown faster than was expected from 500 in 2002 to 26000 today, ${ }^{1}$ and it is clearly hazardous to grow a regular supply of this flammable resinous plant at home in a basement. But it is muddled thinking to suggest that the solution is for doctors to prescribe it.

It does make sense for doctors to be involved, though. We are at an awkward stage in marijuana's development because it is a potentially useful, but illegal, herbal product that the government is prepared to tolerate in certain circumstances. It would be much better for the government to specify criteria that must be met for an individual to be permitted to use marijuana. The doctor's role would then be to certify that a patient met these criteria. This is not the same as a doctor making a diagnosis and deciding to prescribe a drug for a defined indication. This is more akin to certifying that a patient meets the government's criteria for a disabled parking permit. The doctor does not suggest the patient should drive or that a disabled parking place would be good for them, just that they do fall into the category of person that the government says may have one.

It is time the government made up its mind. Does it want marijuana to become a medicine? If it does, it should work with the pharmaceutical companies to ensure that this is a properly researched and developed drug. At the moment, marijuana is a herbal product and not a medicine. Doctors should not allow themselves to be lulled into prescribing it.

\section{References}

1. Harper government announces proposed new marihuana for medical purposes regulations - changes improve public safety, maintain patient access. Ottawa $(\mathrm{ON})$ : Health Canada; 2012. Available: www.hc-sc.gc.ca/ahc-asc/media/nr-cp /_2012/2012-193bkc-eng.php (accessed 2013 Feb. 14).

2. Ware MA, Wang T, Shapiro S, et al. Smoked cannabis for chronic neuropathic pain: a randomized controlled trial. CMAJ 2010;182:E694-701.

Competing interests: See www.cmaj.ca/site/misc/cmaj_staff.xhtml

Affiliation: John Fletcher is Editor-in-Chief, CMAJ.

Correspondence to: $C M A J$ editor, pubs@cmaj.ca

CMAJ 2013. DOI:10.1503/cmaj.130267 